\title{
Some immunological interactions between mother and foetus
}

\author{
C. A. Clarke \\ M.D., F.R.C.P., F.R.S. \\ Professor of Medicine, University of Liverpool, Ashton Street, Liverpool, L69 3BX
}

From the point of view of a practising medical man, the title of this paper is likely to suggest only the effects of $\mathrm{Rh}$ incompatibility and perhaps to a lesser extent ABO incompatibility between mother and foetus. However, in its widest context the concept also can be extended to antigens on leucocytes (only briefly mentioned here), and also to those on tumour cells. Furthermore, there are immunological interactions between mother and foetus in animals, particularly that occurring in haemolytic disease of the newborn foal and of the piglet. These topics will all be discussed in this paper though the emphasis is on Rh-haemolytic disease and its prevention.

\section{(1) Rh-haemolytic disease and its prevention}

It is now generally agreed that immunization of Rhesus-negative women by their Rhesus-positive babies can usually be prevented by the intramuscular injection of anti-D gammaglobulin given to the mother shortly after delivery (see for example Clarke, 1970). The effectiveness of the method has drawn attention not only to many aspects of the $R h$ situation but also to problems of graft rejection, and some points which seem to be of particular current interest will be discussed in this paper.

\section{Failures of prophylaxis}

In all countries using anti-D prophylaxis, a small failure rate has been found. This is about $0.5 \%$ at 6 months after delivery and a further $0.5 \%$ after a subsequent $\mathrm{Rh}$-positive pregnancy. If nothing is done the figures are $8.5 \%$ after delivery and a further $8.5 \%$ after a subsequent $\mathrm{Rh}$-positive pregnancy.

The main reason for failure is that occasionally primary immunization without overt antibody formation ('priming', or 'sensibilization') occurs during pregnancy or after a transfusion, and when this happens the anti-D given may be too late. A Liverpool male volunteer in whom this occurred was an Rh-negative man aged 70 who was 'NDA' (no demonstrable antibodies) on ioutine testing. $\mathrm{He}$ was given $5 \mathrm{ml}$. of $\mathrm{Rh}$-positive foetal blood, and 30 minlater his foetal cell score was 114 per 50 low power fields; $48 \mathrm{hr}$ later it was 0 and at that time anti-D began to be detectable. It was then found that he had had a blood transfusion in the 1914-18 war and clearly primary immunization had taken place as a result. If he had been a young woman he might have been treated at $30 \mathrm{~min}$ after his 'transplacental haemorrhage' (TPH) and then (later) would have been considered a failure.

Another line of argument in favour of 'priming' during pregnancy as a cause of failure stems from a consideration of the size of the TPH after delivery. Thus, although Woodrow \& Donohoe (1968) have shown that the chances of immunization rise as the size of the TPH increases, yet in many of the failures no foetal cells have been found and this is almost certainly because the cell survival has been shortened even though no demonstrable antibodies can be detected by conventional methods.

A possible way of avoiding this type of failure is to give anti-D during pregnancy and this is being done on a large scale both in Canada and Germany, with clinical trials in Winnipeg, Edmonton, Vancouver and Düsseldorf (Bowman, 1970). It is too early yet to assess the effects, but Bowman (1970) reports that in Winnipeg there has been a reduction from 15 to $5 \%$ of demonstrable foeto-maternal bleeds during the third trimester and following delivery.

Another occasional reason for failure is the giving of an insufficient dose of gammaglobulin and this may occur in about $0.1 \%$ of deliveries where the TPH is over $50 \mathrm{ml}$ (Borst Eilers, personal communication, 1970). These very big foeto-maternal haemorrhages give rise to a striking degree of neonatal anaemia, and this, where a mother is $\mathrm{Rh}$ negative, is an absolute indication to examine the maternal blood and make a rough estimate of the amount of foetal blood present. Borst Eilers considers that protection against immunization is usually obtained with doses of anti-D ranging from 4 to $50 \mu \mathrm{g} / \mathrm{ml}$ of foetal red cells with a mean ratio of $25: 1$, while $2-20 \mu \mathrm{g} / \mathrm{ml}$, with a mean ratio of $8: 1$, is usually not enough. With intramuscular injection Borst Eilers thinks there seems no harm in giving the entire dose of anti-D all at the same time, but Keith et al. (1970) citing an actual case where a 
1000-ml transfusion of $\mathrm{Rh}$-positive blood was involved, gave a total of $17,700 \mu \mathrm{g}$ at $12-\mathrm{hr}$ intervals for 8 days. No immune antibodies were present after 8 months, but there has not yet been a second pregnancy. No adverse effects were noted. With intravenous gammaglobulin the dose can be considerably smalle. (Börner et al., 1969), but it should always be given in divided doses.

Some recent work on a large number of male volunteers by Pollack et al. (1972) demonstrates how well even a small dose of anti-D does in fact protect. They divided $178 \mathrm{Rh}$-negative men into six groups consisting of a treated and control series. Each volunteer received one intravenous injection of whole Rh-positive blood varying from 25 to $100 \mathrm{ml}$. Within $72 \mathrm{hr}$ each treated man received exactly $1 \mathrm{ml}$ of immunoglobulin containing $267 \mu \mathrm{g}$ of anti-D, whereas the control groups received a gammaglobulin devoid of antibodies to human red cells. All were carefully followed up for 6 months and those with no anti-D antibodies were then challenged with $0.2 \mathrm{ml}$ of whole blood. One week later a serum sample from all the volunteers was analysed serologically. It will be seen from Table 1 that this particular lot of anti-D protected against $12.0 \mathrm{ml}$ of packed cells or $35 \mathrm{ml}$ of whole blood, and the fact that no antibody was found even after a booster dose was particularly encouraging. Pollack argues from his data that only $65-70 \%$ of Rh-negative individuals are susceptible to being immunized to a single injection of $\mathrm{Rh}$-positive red cells, no matter how large, though he agrees that it is impossible to conclude from this that the other $30-35 \%$ are genetically incapable of being immunized and only subsequent injections of blood given to the nonresponders several months later will resolve this point. He also points out the differences in the results between treated and control subjects. If passively administered antibody acted merely to reduce the concentration of antigen reaching immunocompetent cells, the slopes of regression lines drawn for both groups (deducible from data in Table 1) would have been expected to be the same, but this is not the case. Pollack thought that one possible explanation for the difference (which showed the treated men to have more protection than would have been expected, even though after the breakthrough the immunization rate goes up more sharply, is that antibody acts on some target organ, e.g. the macrophage, to interfere with processing, for the significance of the change in slope is that the antigenicity of the red cells appears to be reduced.

\section{Mechanisms of protection}

Before considering the way in which anti-D may cause suppression of the immune response it is useful to recall that there are two naturally occurring mechanisms by which haemolytic disease of the newborn (HDN) is usually prevented. The firste concerns ABO HDN and the second Rh HDN.

TABLE 1. Protection study in 178 volunteers (Pollack, personal communication, 1970)

1. $25,35,45,55,75$ and $100 \mathrm{ml} \mathrm{Rh}$ positive blood injected i.v. into six groups of $\mathrm{Rh}$-negative male volunteers.

2. Three days later, $267 \mu \mathrm{g}$ of anti-D or $1 \mathrm{ml}$ of normal $\mathrm{IgG}$ given to treated or control series respectively.

3. Serum samples obtained from each man at monthly intervals for 6 months.

4. Each volunteer then given $0.2 \mathrm{ml}$ of blood (i.v.) as a booster.

5. Serum sample obtained 1 week later.

Incidence of immunization in groups of volunteers given varying volumes of Rh-positive blood (Pollack, personal communition, 1970)

\begin{tabular}{llcccccc}
\hline \multicolumn{7}{c}{ Volume of packed rbc given (ml) } \\
\cline { 3 - 8 } & & $\begin{array}{c}11 \cdot 6 \\
(25 \mathrm{ml} \\
\text { of blood) }\end{array}$ & $\begin{array}{l}13 \cdot 4 \\
(35)\end{array}$ & $\begin{array}{c}18 \cdot 1 \\
(45)\end{array}$ & $\begin{array}{c}21 \cdot 2 \\
(55)\end{array}$ & $\begin{array}{c}30 \cdot 1 \\
(75)\end{array}$ & $\begin{array}{c}37 \cdot 5 \\
(100)\end{array}$ \\
\hline \multirow{3}{*}{ Untreated } & Fraction & $7 / 16$ & $6 / 12$ & $11 / 19$ & $5 / 8$ & $7 / 11$ & $13 / 20$ \\
& immunized & $(43 \cdot 8 \%)$ & $(50 \cdot 0 \%)$ & $(57.9 \%)$ & $(62 \cdot 5 \%)$ & $(63 \cdot 6 \%)$ & $(65 \cdot 0 \%)$ \\
\multirow{3}{*}{ Treated } & Fraction & $0 / 19$ & $0 / 18$ & $3 / 18$ & $2 / 8$ & $4 / 12$ & $6 / 17$ \\
& immunized & $(0 \%)$ & $(0 \%)$ & $(16 \cdot 7 \%)$ & $(26 \cdot 0 \%)$ & $(33 \cdot 3 \%)$ & $(35 \cdot 3 \%)$ \\
\hline
\end{tabular}


Naturally occurring protection against $A B O H D N$ and $R h H D N$

Below are set out the main points of difference between these two diseases, and (3) is the one particularly relevant.

\section{ABO HDN}

(1) First baby often affected.

Reason: Anti-A and anti-B are naturally occurring and are mostly 19S which will not cross the placenta. Some 7S, however, may be present, either 'idiopathic' or produced in response to some non-human antigen which may be present in an injection containing A-specific horse serum. A baby of any birth rank can, therefore, be affected.

(2) O mothers much the most liable.

Reason: The naturally occurring anti-A or anti-B from $\mathrm{O}$ mothers contains $7 \mathrm{~S}$ antibody (which can cross the placenta) much more often than does the antibody from A or B mothers.

(3) There are two naturally protective mechanisms: (a) all babies (secretors and non-secretors) have blood group substances in the body fluids which 'mop up' the antibody from the mother thereby preventing most of it from attacking the red cells. Secretors have more than non-secretors, but it is present in both; (b) the antigens on foetal red cells are immature (see below).

(4) An unaffected baby often follows the birth of an affected one. Why this is so is unexplained.

(5) Relevance of secretor status of baby is uncertain. The secretor molecule is large and does not cross the placenta except at delivery. If secretor substance causes immunization it would be the later babies who would be affected. The mother's antibody titre usually falls rapidly after delivery, but on the contrary after she has had a secretor baby it rises markedly.

It will be seen that under point 3 there is an inherent contradiction. If the $\mathrm{ABO}$ antigens on foetal red cells are immature, they are less than normally antigenic, and if this is so one would not expect that ABO incompatibility would be protective against $\mathbf{R h}$ immunization, whichever theory of protection is correct (see p. 204-5). An explanation may be that in some infants the antigens are better developed than in others, and those in which this is so would be better protected from Rh HDN-but they might, on the other hand, be expected to be

\section{Rh HDN}

(1) First baby rarely affected.

Reason: First baby immunizes the mother (usually by TPH at delivery) but $\mathrm{Rh}$ antibody not generally made until weeks or months after the first baby is born and may even need the stimulus of a small TPH from a second Rh-positive foetus.

(2) O mother least liable.

Reason: $\mathrm{Rh}$-positive babies born to $\mathrm{O}$ mothers will be, in about $50 \%$ of cases, either group $\mathrm{A}$ or group $\mathrm{B}$ and therefore $\mathrm{ABO}$ incompatible and protected (see 3 below). An A mother will usually have an ABO compatible baby, only $B$ being incompatible.

(3) Where there is foeto-maternal $\mathrm{ABO}$ incompatibility there is very unlikely to be immunization to $\mathrm{Rh}$. This is because the mother's anti-A or anti-B either haemolyses, removes to a site where there are few or no antibody forming cells, or blocks the $\mathrm{Rh}$ positive foetal cells (see also page 202).

(4) Subsequent Rh-positive babies are usually affected.

(5) Secretor status of baby irrelevant.

more liable to get ABO HDN. It might possibly be found therefore that $\mathrm{Rh}$-negative mothers with $\mathrm{Rh}$ positive ABO incompatible children who did not become immunized to $\mathrm{Rh}$ had more babies with ABO HDN than did controls, but this could be difficult to establish as the diagnosis of ABO HDN is far from easy.

In discussing the antigenicity of foetal red cells another point worth mentioning is the situation with $A_{1}$ and $A_{2}$ antigens. $A_{1}$ adult cells have four times as many antigen sites as adult $\mathbf{A}_{2}$ cells, and infants' $A_{1}$ 
cells react on testing in the same way as adult $\mathrm{A}_{2}$ cells. It follows from this that infants' $A_{1}$ cells are immature, and that they will in the course of time acquire more antigen sites. One assumes that infants' $\mathrm{A}_{2}$ cells will have still fewer antigen sites on them than those of infants who are $A_{1}$, and this would lead us to expect $\mathrm{A}_{2}$ babies to be only rarely attacked by $\mathrm{ABO} \mathrm{HD}$. This is in fact what is observed.

\section{Protection by anti-D against Rh HDN}

For immunization to occur there must probably be a serie's of separate 'hits' by the antigen complexes on the antibody forming cells. Priming is thought to be associated with proliferation of the virgin lymphoid cells (X cells) to give a large population of memory ( $Y$ ) cells. Further contact of antigen with these leads to differentiation into $Z$ cells, which form the antibody. The $Z$ cells have probably only a limited life-span and the continued production of antibody (and the secondary response) depend on the progress of a pool of $Y$ cells which are transformed into $\mathrm{Z}$ cells by subsequent antigenic stimuli. There is a further complicating factor in that two types of antibody-forming cellsthymus dependent ones and those from the bone marrow-are essential to the process of immunization, but the exact way in which they are interdependent is uncertain at present (see Woodrow, 1970 , for references).

(a) The blocking hypothesis. When passive anti-D is injected, what probably happens is that it competes against the antibody-forming cells of the recipient for the antigen sites on the foreign red cells. Depending on the number covered and the efficiency of the particular antibody used, these antigen sites are then prevented from coming into contact with the antibody-forming cells of the mother (or recipient) which will then not begin making immune antibodies. Antibodies vary in their binding capacity, or 'affinity', and the better the antibody-that is the higher the affinity - the less will be needed to effect protection.

Animal work supporting the blocking hypothesis is provided by Pierce (1969) who used an in vitro culture system to measure the capacity of mouse spleen cells to haemolyse sheep red blood cells (SRBC). Anti-SRBC antibody specifically suppressed the haemolysin response and the degree of suppression was directly related to the amount of antibody used. When this was constant and increasing amounts of antigen were added, considerable immunosuppression occurred over a wide range of antigen doses, but when the dose of antigen was raised still further the suppression was overcome. This demonstrated that the antibody-forming cells could still respond to antigen and it therefore seemed very unlikely that there was a direct effect of the antibody on these cells. The simplest interpretation was that up to a certain dosage of antigen there was enough antibody present to bind with the combining sites on the red cells, and after this, with the highest amounts of antigen, there were enough sites free to produce an immune response. Further experiments on the same lines but involving the macrophages (see below) led Pierce to conclude that blocking, and thus immunosuppression, occurred when antibody came into contact with antigen which had been through the macrophages.

Macrophages are large leucocytes which can be wandering or fixed, and they carry the antigen to the antigen-sensitive-that is the antibody-forming cells. It is thought that their role is to alter in some way ('process') the foreign antigen before handing it on to the antibody-forming cells, and it is likely that the blocking of the sites by the injected antibody interferes with this processing. The importance of the macrophages was shown by Ryder \& Schwartz (1969). They injected mice with foreign antigen and also antibody against that antigen and macrophages were then taken from the animals and transplanted into mice which had received antigen only. The recipients did not make antibody-i.e. the exposure of the macrophages to the antibody had rendered them incapable of 'processing' the antigen after being transplanted. Control macrophages from animals not passively immunized produced an immune response.

(b) The hypothesis that anti-D inhibits centrally. It has been suggested that the protective action is on the antibody-forming cells themselves, and that by a feedback mechanism immune antibody is prevented from being made. This theory was based on the work of Rowley \& Fitch (1964) who found that when normal rat spleen (that is, antibody-forming) cells were exposed in vitro to anti-sheep erythrocyte serum and then transferred to irradiated recipients, the cells did not make an early antibody response when challenged with sheep erythrocytes. On the other hand, Pierce (1969) and Ryder, Kilham \& Schwartz (1969) showed in similar experiments in mice that immunization is not suppressed by exposure of lymphoid cells to serum against an injected antigen, though it was prevented by the exposure of macrophages to such serum. It is possible, therefore, that in the Rowley \& Fitch (1964) work the reason for the prevention of the haemolysis was that the macrophages rather than the lymphoid cells were involved. More evidence against the hypothesis is also provided by Dixon, Jacot-Guillarmod \& McConahey (1967). Working with the antigen keyhole limpet haemocyanin (KLH) in rabbits, they found that when anti-KLH was given $24 \mathrm{hr}$ after the antigen, 
immune antibody was more effectively suppressed than when it was given before, clearly arguing against a direct immunosuppressive effect on the antibody-forming cells. Finally, if central inhibition were the explanation, the speed of clearance of $\mathrm{Rh}$ positive foetal cells from the mother's circulation in the prophylaxis against $\mathrm{Rh}$ immunization would be irrelevant, which it does not appear to be. The relationship of clearance to protection by injected anti-D is uncertain, but they are likely to prove closely connected.

(c) Specificity of suppression in the case of red cell antibodies. There is conflicting evidence as to whether the fact of coating with antibody interferes with the processing of the entire red cell, so that antibody formation against all the antigenic determinants on it is suppressed, or whether the protection is antigen-specific. Though human antigenantibody reactions may not follow the same pattern, there is evidence for specificity in the results obtained by Pollack et al. (1968). They prevented anti- $\mathrm{Hg}^{\mathrm{A}}$ production in $\mathbf{H g}^{\mathrm{A}} \mathrm{Hg}^{\mathrm{F}}$-negative rabbits injected with $\mathrm{Hg}^{\mathrm{A}} \mathrm{Hg}^{\mathrm{F}}$ rabbit erythrocytes by administering passive anti- $\mathrm{Hg}^{\mathrm{A}}$ antibody, but they did not prevent anti-Hg ${ }^{F}$ production. On the other hand, in the guinea pig Henney \& Ishizaka (1968) found passive administration against one portion of the IgG molecule also suppressed antibody formation against the other portion. In this case only one antigen site could have been covered by the antibody and yet both types of antibody were suppressed, and it would seem that here the whole antigenic complex is prevented from reaching the antibody producing cells. Furthermore, the protection against Rhesus immunization afforded by ABO incompatibility is nonspecific, and the situation is the same with other antibodies such as Kell. For instance, in a Liverpool series (unpublished) no anti-Kell antibodies were produced in $753 \mathrm{Rh}$-negative women treated by anti-D, and a few would have been expected since it is known that the gammaglobulin does not contain anti-Kell. Nor were other immune antibodies found, except for anti-Leb (but Lewis is not primarily a blood group antigen) and these findings have to be compared with those of Queenan et al. (1969) who found 299 'irregular' antibodies in 18,378 consecutive obstetric patients who had not been treated with anti-D. There is also more information on the matter from Pollack (1970, personal communication). He looked for other antibodies in the treated among the $178 \mathrm{Rh}$-negative volunteers (see above, page 200) and found none (except again for an occasional Lewis). The combined evidence therefore strongly suggests that protection in Man is non-specific and that the $R h$ blood groups at any rate behave quite differently from many animal systems.

An experiment designed to test for specificity is in progress at the present time in Liverpool. Rhnegative, Kell-negative volunteers are being injected with tagged Rh-positive, Kell-positive erythrocytes and then some are injected with anti-Kell. If this is specific, only anti-Kell formation should be prevented, but not anti-D formation. On the other hand, if the action is non-specific, the giving of antiKell should prevent the volunteers from forming both types of antibody.

\section{Blocking of antigen sites in renal transplantation work}

It is useful to consider suppression according as to whether the afferent, central or efferent limb of the immune response is involved. Anti-D certainly concerns the afferent side and possibly the central response as well, and the same is true of some animal experiments, but in organ transplantation, the efferent side in addition has to be considered, and the work of Batchelor and his colleagues (1970) will now be mentioned.

Protection of the graft involves, as in Rh prophylaxis, the giving of antibody to the recipient of the foreign antigen, but for a different reason. It is done so that the graft is partially coated with humoral antibody and this prevents the cellular antibody, which is the damaging one, from destroying the graft. The giving of the humoral antibody is a 'holding operation', for in due course it is hoped that the recipient of the graft will himself form humoral antibody against it, and this will in its turn coat some of the antigen sites on the graft and protect it from the invading lymphocytes. The object, therefore, is not to prevent the recipient of the graft from making antibody at all, but to protect the graft while he does so, and it is the cellular antibodies which are so lethal to the graft. The procedure in an actual case, in a boy of 8 needing a kidney and whose mother was to be the donor, was to inject her lymphocytes into her husband and thereby raise 'anti-mother' gammaglobulin. Papain treatment of the gammaglobulin removed the $\mathrm{Fc}$ (complement fixing) piece so that the kidney cells were coated, not lysed. The boy was given this gammaglobulin at the same time as, and after, the grafted kidney, and appeared to need much less immunosuppressive treatment than usual. The longterm difficulty with this boy was to establish the right balance so that enough antigen sites were left exposed to stimulate humoral antibody formation, but not so many that the graft was destroyed by the cellular response.

A similar type of experiment had earlier been carried out in rats (French \& Batchelor, 1969) but 
here the rats did not make their own enhancing antibody.

It is possible to induce endogenous enhancing antibody formation by giving i.v. spleen cells (Stuart, Tutsuo \& Fitch, 1968), or spleen cell antigen (Wilson et al., 1969). This is likely to produce more complete protection as there is a well documented 'tolerogenic' effect in such preparations.

\section{(2) Haemolytic disease of the newborn in the foal}

This disorder has many parallels with $\mathrm{Rh}$. Thus the first foal is rarely affected and immunization is thought to take place by transplacental passage of cells at delivery. Unfortunately, however, the erythrocytes of the foal are mature at birth and it is, therefore, not possible to score foetal cells in the maternal circulation. Also in contrast to Man, the immune antibody formed against the foal's incompatible antigens is usually of the agglutinating type (Roberts, 1957), and this may be why it does not cross the placenta though it is secreted in the colostrum where for a short time it is extremely toxic. A foal normal at birth rapidly becomes ill on suckling and may be dead within $36 \mathrm{hr}$. Since after this time the milk contains no more antibody, the disease can be effectively prevented by weaning (Franks, 1962), and this being so it is perplexing to read that the disease is of considerable economic importance in the bloodstock industry and that new methods of exchange transfusion were being devised (Cambridge Daily News, 20 August, 1966). The reason may be that weaning, though easy in theory, is difficult in practice (since a little colostrum may be taken), or it may even not be known that the foal is at risk. Also, a foster mother may be hard to come by, and colostrum appears to be necessary to ensure that the foal thrives.

By analogy with Man the disease ought to be preventable by giving the mare gammaglobulin against the incompatible antigens, but bloodstock breeders are very sensitive to any suggestion that there is an inherited disease in their animals.

(3) Haemolytic disease of the newborn in the piglet (Roberts, 1957)

Here, too, the antibody is transmitted to the offspring in the colostrum. The sow can be immunized by certain foetal red cell antigens during pregnancy (though the pig A antigen is not responsible since it is only formed after birth), and also (formerly) by the administration of swine fever vaccine, which was made from pooled pigs' blood. The disease has been produced experimentally by the injection of the sow during pregnancy with repeated doses of the incompatible (heterozygous) male's blood. Those piglets in the litter which were incompatible were all killed by HDN, while those which were compatible were unaffected.
(4) Immunological factors in choriocarcinoma

A stimulating though unproven suggestion regarding cancer is that most of us at some time in our lives develop neoplasia but that usually we eliminate the abnormal cells, possibly by a mechanism similar to that of graft rejection. Modest support for the hypothesis is afforded by the observation that women with a history of allergy may be less at risk for subsequent cancer than controls (Mackay, 1966). However, this survey was retrospective and the sex difference remains unexplained.

A more profitable approach concerns choriocarcinomata. Because these malignant tumours are derived from foetal tissue one of the chromosomes in each pair is paternal in origin and the growth must be considered as a partially allogeneic graft. This might have some relation to the progress or halting of the disease (see Clarke 1962, 1968), which as is well known, runs an extremely unpredictable course. $A$ priori, it would seem reasonable that where the mother and the cancer had similar histocompatibility genes the disease would take a more sinister course, and conversely, where the blood groups on the cancer cells were incompatible it might be kept in check or rejected. There is some support for these views. Scott $(1962,1968)$ found that the patients' ABO blood group distribution showed a shift away from $\mathrm{O}$ to $\mathrm{A}, \mathrm{B}$ and $\mathrm{AB}$ which was in keeping with the idea that foeto-maternal compatibility is an aetiological factor, and furthermore the growth is commoner in inbreeding communities (Azar, 1962; Iliya, Williamson \& Azar, 1967).

Ben-Hur, Robinson \& Neuman (1965) found that in three patients with choriocarcinoma, skin homografts from the husband were accepted, whereas those from other donors were rejected. The authors suggest that since some hydatidiform moles undergo transformation to choriocarcinomata every woman with a mole should be grafted with her husband's skin. Where this homograft is not rejected they advise against further pregnancies (presumably for about 2 years) since the risk of development of choriocarcinoma would be high and pregnancy would confuse the diagnosis.

Møgensen \& Kissmeyer-Nielsen (1967, 1968) carried out family studies on choriocarcinoma cases in order to establish whether the matings could produce zygotes which were histocompatible with the mothers, the antigens investigated being the important histocompatibility antigens, i.e. the $\mathrm{ABO}$ and those at the HLA locus, and the authors found a high degree of histocompatibility. Since there is about a $50 \%$ chance of any donor and recipient being compatible or incompatible for the major histocompatibility genes, this could mean that in $50 \%$ of those cases where the mole began to become malignant the cancer might be checked. 
On the other hand, not all the evidence points to compatibility being important. While the observations of Robinson and his colleagues $(1963,1967)$ are in agreement about the skin grafting results, yet when they typed the leucocyte antigens of the patient and her husband they did not find compatibility. The explanation put forward was that the tumour induces maternal tolerance to the paternal antigens it carries. Something like this may occur in normal human pregnancy for it has been shown that in the mouse post-partum females exhibit specific tolerance to the transplantation antigens of the mating male (Breyere \& Barrett, 1960). The mechanism for the induction of the tolerance is not clear, but the antigens of the sperm are not involved (Porter \& Breyere, 1964).

The latest information on choriocarcinoma comes from Bagshawe and his colleagues (1971) who report on 260 cases with the disease. The data show that the risk of developing it is critically related to the ABO groups of both the woman and her husband. Women of group $\mathrm{A}$ married to males of group $\mathrm{O}$ seem to have the highest risk, whereas women of group A married to males of group A have the lowest: the relative risk of these two groups was found to be 10.4/1. The spontaneous regression of trophoblast after evacuation of hydatidiform mole happened most commonly in women mated to males of their own $\mathrm{ABO}$ phenotype. Group $\mathrm{AB}$ patients tend to have rapidly progressive tumours which do not respond well to chemotherapy.

The data indicate that although genetic factors strongly affect the development of choriocarcinoma, yet the mechanisms are not readily explained by current concepts of tumour/host and materno/foetal interaction.

A considerable part of this paper is based on one given at the Conference on Advanced Medicine, Royal College of Physicians, 1971 (published by Pitman Medical and reproduced by kind permission).

\section{References}

Azar, H.A. (1962) Cancer in Lebanon and the Near East. Cancer, 15, 66.

Bagshawe, K.D., Rawlins, G., Pike, M.C. \& Lawler, SyLviA D. (1971) ABO blood groups in trophoblastic neoplasia. Lancet, i, 553.

Batchelor, J.R., Ellis, F., French, M.E., Bewick, M., Cameron, J.S. \& OGG, C.S. (1970) Immunological enhancement of human kidney graft. Lancet, ii, 1007.

Ben-Hur, N., Robinson, E. \& Neuman, Z. (1965) Possible screening method for prevention of chorionepithelioma in women with hydatidiform mole. Lancet, i, 611 .

Börner, P., Deicher, H., Hoppe, H.H., HitschHold, H., Holtz, S., \& Seifert, A. (1969) Prophylaxe der Rhesussensibilisierung durch intravenöse Gabe von Immunoglobulin G Anti-D. Klinische Ergebnisse und Untersuchungen zur Anti-D-Dosierung. Geburtshilfe und Frauenheilkunde, 29, No. 3, 203.
Bowman, J.M. (1970) Prevention of haemolytic disease of the newborn. British Journal of Haematology, 19, 653.

Breyere, E.J. \& BarretT, M.K. (1960) Prolonged survival of skin homografts in parous female mice. Journal of the National Cancer Institute, 25, 1405.

Clarke, C.A. (1962) Genetics for the Clinician, 2nd edn. Blackwell Scientific Publications, Oxford.

Clarke C.A. (1968) Immunology of pregnancy: Significance of blood group incompatibility between mother and foetus. Proceedings of the Royal Society of Medicine, 61, 1213.

Clarke, C.A. (1970) The prevention of rhesus isoimmunisation. Clinical Genetics, 1, 183.

Dixon, F.J., Jacot-Guillarmod, J. \& McConahey, P.J. (1967) The effect of passively administered antibody on antibody synthesis. Journal of Experimental Medicine, 125, 1119.

Franks, D. (1962) Horse blood groups and haemolytic disease of the newborn foal. Annals of the New York Academy of Sciences, 97, 235.

French, M.E. \& BAtChelor, J.R. (1969) Immunological enhancement of rat kidney grafts. Lancet, ii, 1103.

Henney, C. \& Ishizaka, K. (1968) Studies on the immunogenicity of antigen-antibody precipitates. I. The suppressive effect of anti-L and anti-H chain antibodies on the immunogenicity of human $\gamma \mathrm{G}$ globulin. Journal of Immuno$\log y, 101,986$.

Iliya, F.A., Williamson, S. \& Azar, H.A. (1967) Choriocarcinoma in the Near East. Cancer, 20, 144.

Keith, L., Cuva, A., Houser, K. \& Webster, A. (1970) Suppression of primary $\mathrm{Rh}$-immunisation by anti-Rh. Transfusion, 10, No. 3, 142.

MACKAY, W.D. (1966) The incidence of allergic disorders and cancer. British Journal of Cancer, 20, No. 3, 434.

Møgenson, B. \& Kissmeyer-Nielsen, F. (1967) Histocompatibility in generalised choriocarcinoma: a family study. Bulletin of the European Society of Human Genetics, $1,64$.

Møgensen, B. \& Kissmeyer-Nielsen, F. (1968) Histocompatability antigens on the HL-A locus in generalized gestational choriocarcinoma: a family study. Lancet, $\mathbf{i}, 721$.

PIERCE, C.W. (1969) Immune response in vitro. II. Suppression of the immune response in vitro by specific antibody. Journal of Experimental Medicine, 130, 365.

Pollack, W., Ascari, W.Q., Kochesky, R.J., O'ConNor, R.R., Ho, T.Y. \& TRIPODI, D. Studies on Rhesus prophylaxis. I. The relationship between doses of anti-R $h$ and the size of the antigenic stimulus. Transfusion (in press).

Pollack, W., Gorman, J.G., Hager, H.J., Freda, V.J. \& TRIPODI, D. (1968) Antibody-mediated immune suppression to $\mathrm{Rh}$-factor. Animal models suggesting mechanism of action. Transfusion, 8, 134.

Porter, J.B. \& BREYere, E.J. (1964) Studies on the source of antigenic stimulation in the induction of tolerance by parity. Transplantation, 2, 246.

QueENAN, J.T., SMITH, B.D., HABER, J.M., JefFrey, JACQUELINE \& GADOW, H.C. (1969) Irregular antibodies in the obstetric patient. Obstetrics and Gynecology, 34, 767.

Roberts, G. Fulton (1957) Comparative Aspects of Haemolytic Disease of the Newborn. Heinemann Medical Books, London.

Robinson, E., Shulman, J., Ben-Hur, N., Zuckerman, H. \& NeumaN, Z. (1963) Immunological studies and behaviour of husband and foreign homografts in patients with chorionepithelioma. Lancet, i, 300.

Robinson, E., Ben-Hur, N., Zuckerman, H. \& Neuman, Z. (1967) Further immunologic studies in patients with chorionepithelioma and hydatidiform mole. Cancer Research, 27, 1202. 
Rowley, D.A. \& Fitch, F.W. (1964) Homeostasis of antibody in the adult rat. Journal of Experimental Medicine, $120,987$.

Ryder, R.J.W., Kilham, K. \& Schwartz, R.S. (1969) Immunosuppression by antibody. Transplantation Proceedings, 1, 524.

RYDER, R.J.W. \& SCHWARTZ, R.S. (1969) Immunosuppression by antibody. Localisation of site of action. Journal of Immunology, 103, 970.

SCOTT, J.S. (1962) Choriocarcinoma: observations on the aetiology. American Journal of Obstetrics and Gynecology, 83, 185.

ScoTT, J.S. (1968) Histocompatibility antigens in choriocarcinoma. Lancet, i, 865.
Stuart, F.P., Tutsuo, S. \& Fitch, F.W. (1968) Rejection of Renal Allografts: Specific Immunologic Suppression. Science, 160, 1463.

Wilson, R.E., Rippin, A., Dagher, R.K., Kinneart, P. \& BusCH, G.J. Prolonged canine renal allograft; survival after pretreatment with solubilized antigen. Transplantation, 7 , No. 5,360 .

Woodrow, J.C. (1970) Rh Immunisation and its Prevention (Ed. by K. G. Jensen and S-A Killman). Series Haematologica, III, No. 3, 1970, 1, Munksgaard, Copenhagen.

Woodrow, J.C. \& Donohoe, W.T.A. (1968) Rh-immunisation by pregnancy: Results of a survey and their relevance to prophylactic therapy. British Medical Journal, 4, 139. 